\title{
A Carrier Communication Channel Modeling Of Marine Electromagnetic Exploration System Based On Multi Conductor Transmission Line Theory
}

\author{
Xiguo Ren ${ }^{1}$, Yiming Zhang ${ }^{1}$, Haijun Tao ${ }^{1,2}$, Zhihui Zeng $^{2}$ and Jianzhi Ding ${ }^{1}$ \\ ${ }^{1}$ Beijing University of Technology, Beijing 100124 China $;{ }^{2}$ Henan Polytechnic \\ University, Jiaozuo 454003 China \\ xiaoxifree@126.com; ymzhang@bjut.edu.cn; taohj99@hpu.edu.cn; \\ djzh5@163.com;zzhh@hpu.edu.cn
}

\begin{abstract}
Subsea communication system is a key component of marine electromagnetic exploration system. In subsea communication system, only the power line channel model is fully studied, it could help to achieve high-speed and reliable power line carrier communication. In this paper, a channel model is established by using the theory of multi conductor transmission. The single Pi structure, double Pi structure and T structure cable model have been simulated through the Spice. The accuracy of single Pi structure model was verified by measurement and simulation. It provides a guiding role for the whole communication system.
\end{abstract}

Keywords: Marine electromagnetic exploration system; the theory of multi conductor transmission; transmission line model; Spice; the single Pi structure

\section{Introduction}

Power line carrier communication (PLC) is a kind of communication mode that carries on the voice or data transmission by the power line as the information transmission medium [1]. Power lines are widely used in thousands of households, and it is widely and economy used as a communication medium. People have a long history of research on power carrier communication technology. And it was applied to the $10 \mathrm{kV}$ distribution network line communications as long as in 1920s. With the rapid development and the rising demand for a variety of communications, power line carrier communication has become a hot research topic in the domestic and foreign researchers [2]. Subsea communication system is a key component of marine electromagnetic exploration system. In subsea communication system, the whole communication system is constituted by the sending / receiving device and a communication channel between them, which transport the data of subsea depth, temperature, output voltage, output current, and emission frequency and so on. The communication channel is a key factor affecting the communication quality of the communication system. Because it is directly related to the signal attenuation, impedance and noise, and there is a very large impact on the transmission and reception. In the marine electromagnetic exploration system, a large number of power electronic devices are used. It presents new problems and challenges to the research of the component impedance model. Therefore, this paper mainly focuses on the research of the subsea communication channel.

In subsea communication system, only the power line channel model is fully studied, it could help to achieve high-speed and reliable power line carrier communication. In recent years, the scholars have a lot of research on the attenuation, impedance and noise of power line. In literature [3], a channel model is established and validated the laboratory simulation circuit based on two-conductor transmission line. In literature [4], a 
distribution network power line communication channel model is built based on the node admittance matrix. The test frequency is limited to $120 \mathrm{kHz}$ or less. In literature [5], the attenuation model of low-voltage lines is established based on two-conductor transmission lines and port network theory. While only a small number of scholars have carried out a simple study on the PLC system in the control system of subsea production. In literature [6], there is a brief introduction on the principle of subsea PLC, the structure and modulation. And literature [7] introduces several major modulation schemes. Literature [8-10] gives the design method of subsea wave communication router. But these documents simply introduce the working principle of the communication system, the composition of the modulation and demodulation equipment device [11]. The design and analysis of the actual communication system are rarely involved. Overall, the current research into the model is not directed at the marine electromagnetic exploration system. The model of transmission line has not yet been deeply studied for marine electromagnetic exploration system.

The transmission line of the marine electromagnetic exploration system is usually more than a few kilometers, and the high frequency communication signal is difficult to be described by the top-down method. In this paper, a channel model is established by using the bottom up method. The model parameters are obtained from the bottom up method through theoretical calculation, which has good generality and flexibility, and could well describe the relationship between the channel characteristics and the model parameters. The impedance model of the Towing cable is determined through field measurements based on the impedance measurement. The correctness of the model is verified by experiments. The transmission law of the marine PLC signal would be further study by this model.

\section{Synopsis of Marine Electromagnetic Marine Communication System}

The marine electromagnetic exploration system adopts subsea system back to platform above water. It is divided into four parts: maritime control section, maritime supply section, Towing cables and subsea electromagnetic marine section. Its structure diagram is shown in Figure 1.

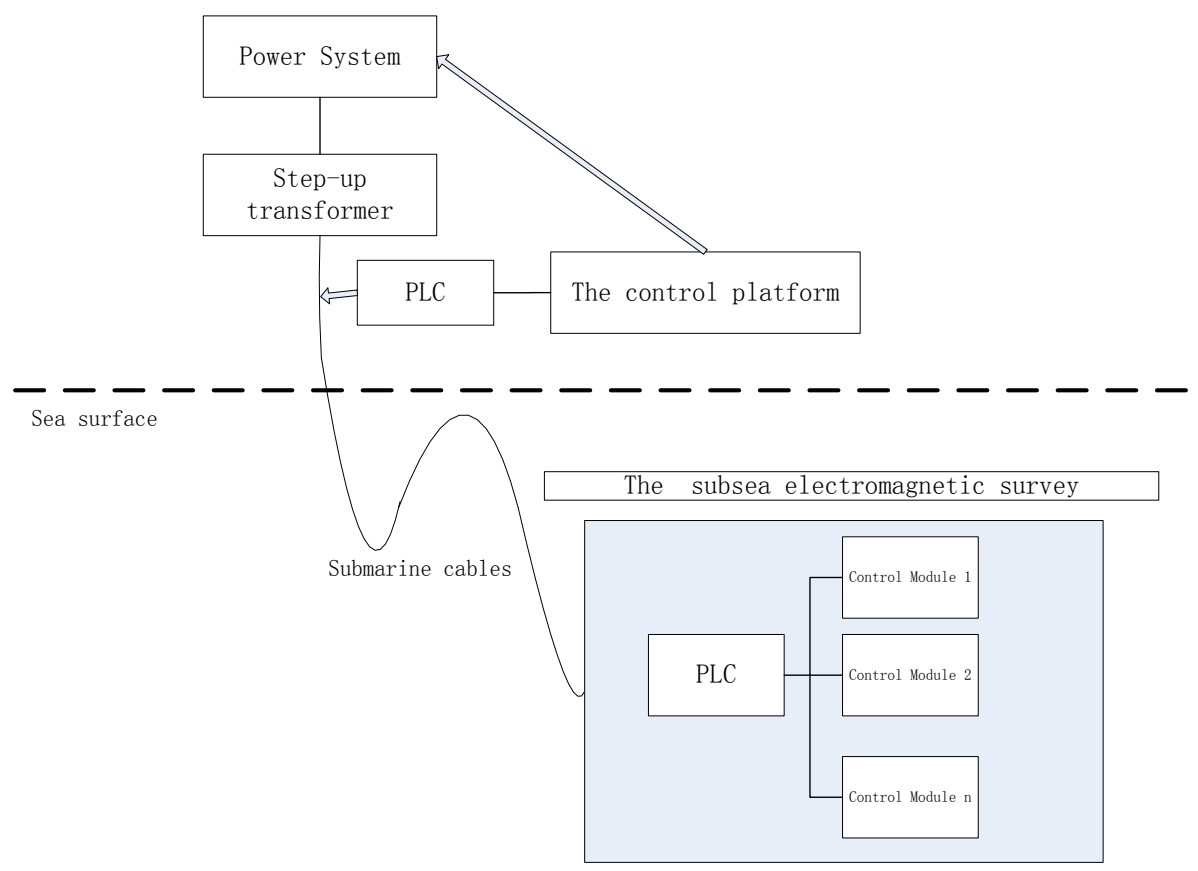

Figure 1. The Structure Diagram of the Marine Electromagnetic Exploration System 
From the Figure 1, the maritime carrier equipment is located in the control platform, connected to the towing cables. And the subsea carrier equipment located in the electromagnetic marine section. The power / signal transmission of whole system is connected by a several thousand meters towing cable. Because the control modules of the electromagnetic marine section transmit the signal by the internal signal line, and the carrier signals cannot be transmitted across the transformer. The communication channel of the PLC communication is the terminal of the maritime towing cable to the terminal of the subsea towing cable. In order to achieve high-speed and reliable power line communications, it is necessary to have a good understanding of the power line channel model. Therefore, the main purpose of this paper is to establish the channel model of marine electromagnetic communication.

\section{Parameter Calculation of Unit Length Transmission Line in Marine Electromagnetic Exploration System}

Since the transmission line uses the coaxial cable in the marine electromagnetic exploration system. The unit length parameter matrix is R, L, G, C. The distribution conductivity of the transmission line is simulated in literature [12].And its result shows that the electrical conductivity of the e transmission line could be neglected in the range of $30 \mathrm{MHz} \sim 1 \mathrm{~Hz}$. In the marine electromagnetic exploration system the voltage of the towing cable is $3-5 \mathrm{KV}$. Because of the high frequency of power line communication, the skin effect of wire could not be ignored.

Internal to the conductor, the conduction current dominates the displacement current. Therefore, current distribution in the cable conductor could be described by the transmission equation of the transmission line. Assuming that the current density is in the $\mathrm{z}$ direction (along the axis of the wire) and on the symmetry of the wire. It is assumed that the current density is independent of $\mathrm{z}$ and is a function of the wire radius $r$. The conduction equation could be described as.

$$
\frac{\mathrm{d}^{2} J_{z}}{\mathrm{dr}^{2}}+\frac{1}{\mathrm{r}} \frac{\mathrm{d}^{2} J_{z}}{\mathrm{dr}}+\mathrm{k}^{2} J_{z}=0
$$

Here

$$
\mathrm{k}^{2}=-\mathrm{j} \omega \mu \sigma=-\mathrm{j} \frac{2}{\delta^{2}}
$$

$\mu$ is the magnetic permeability of the cable, $\sigma$ is the electrical conductivity of the cable, $\delta$ is the skin depth of the cable, $\mathrm{J}_{\mathrm{z}}$ is the current density at the radius $\mathrm{r}$.

The solution to this equation is

$$
J_{z}=J_{o} \frac{\operatorname{ber}(\sqrt{ } 2 \mathrm{r} / \delta)+\operatorname{jbei}(\sqrt{ } 2 \mathrm{r} / \delta)}{\operatorname{ber}\left(\sqrt{ } 2 \mathrm{r}_{0} / \delta\right)+\operatorname{jbei}\left(\sqrt{ } 2 \mathrm{r}_{0} / \delta\right)}
$$

Where ber(x) and bei(x) are the real and imaginary parts of the first class deputy variable Bessel function. $\mathrm{J}_{0}$ is the current density of wire outer radius at $\mathrm{r}=\mathrm{r}_{0}$.

According to Faraday's law of electromagnetic induction, the magnetic field can be obtained by the product of the conductivity of the conducting cable.

$$
\nabla \times \overrightarrow{\mathbf{J}}=-\mathrm{j} \omega \mu \sigma \overrightarrow{\mathrm{H}}
$$

The current density is only related to the radius $r$ in the $\mathrm{Z}$ direction. So

$$
\frac{\mathrm{dJ}_{z}}{\mathrm{dr}}=\mathrm{j} \omega \mu \sigma \hat{\mathrm{H}}_{\varphi}
$$

Substituting (5) into formula (3) gives the calculation formula of the total impedance and the inner inductance (unit length) of the conductor: 


$$
\begin{array}{r}
\frac{\mathrm{R}}{\mathrm{R}_{\mathrm{dc}}}=\frac{\mathrm{q}}{2}\left[\frac{\operatorname{ber}\left(\sqrt{ } 2 \mathrm{r}_{\mathrm{w}} / \delta\right) \operatorname{bei}^{\prime}\left(\sqrt{ } 2 \mathrm{r}_{\mathrm{w}} / \delta\right)-\operatorname{bei}(\mathrm{q}) \operatorname{ber}^{\prime}\left(\sqrt{ } 2 \mathrm{r}_{\mathrm{w}} / \delta\right)}{\left(\operatorname{bei}^{\prime}\left(\mathrm{q} 2 \mathrm{r}_{\mathrm{w}} / \delta\right)\right)^{2}+\left(\operatorname{ber}^{\prime}\left(\sqrt{ } 2 \mathrm{r}_{\mathrm{w}} / \delta \mathrm{q}\right)\right)^{2}}\right] \\
\frac{\mathrm{L}_{\mathrm{i}}}{\mathrm{L}_{\mathrm{i}, \mathrm{dc}}}=\frac{\mathrm{q}}{4}\left[\frac{\operatorname{bei}\left(\sqrt{ } 2 \mathrm{r}_{\mathrm{w}} / \delta \mathrm{q}\right) \operatorname{bei}^{\prime}\left(\sqrt{ } 2 \mathrm{r}_{\mathrm{w}} / \delta\right)-\operatorname{ber}(\mathrm{q}) \operatorname{ber}^{\prime}\left(\sqrt{ } 2 \mathrm{r}_{\mathrm{w}} / \delta \mathrm{q}\right)}{\left(\operatorname{bei}^{\prime}\left(\sqrt{ } 2 \mathrm{r}_{\mathrm{w}} / \delta\right)\right)^{2}+\left(\operatorname{ber}^{\prime}\left(\sqrt{ } 2 \mathrm{r}_{\mathrm{w}} / \delta\right)\right)^{2}}\right]
\end{array}
$$

Where

$$
\begin{gathered}
\mathrm{R}_{\mathrm{dc}}=\frac{1}{\sigma \pi \mathrm{r}_{0}^{2}}(\Omega / \mathrm{m}) \\
\mathrm{L}_{\mathrm{i}, \mathrm{dc}}=\frac{\mu_{0}}{8 \pi}=0.5 \times 10^{-7}(\mathrm{H} / \mathrm{m}) \\
\operatorname{bei}^{\prime}\left(\sqrt{ } 2 \mathrm{r}_{0} / \delta\right)=\frac{\mathrm{d}}{\mathrm{dr}} \operatorname{bei}\left(\sqrt{ } 2 \mathrm{r}_{0} / \delta\right) \\
\operatorname{ber}\left(\sqrt{ } 2 \mathrm{r}_{0} / \delta\right)=\frac{\mathrm{d}}{\mathrm{dr}} \operatorname{ber}\left(\sqrt{ } 2 \mathrm{r}_{0} / \delta\right)
\end{gathered}
$$

Since the pilot carrier frequency is generally from tens $\mathrm{Hz}$ to hundreds $\mathrm{MHz}$, the unit length of the total impedance and the inner inductance can be simplified as

$$
\begin{aligned}
& \mathrm{R}=\frac{1}{2 \mathrm{r}_{0}} \sqrt{\frac{\mu}{\pi \sigma}} \sqrt{\mathrm{f}}(\Omega / \mathrm{m}) \\
& \mathrm{L}_{\mathrm{i}}=\frac{1}{4 \pi \mathrm{r}_{0}} \sqrt{\frac{\mu}{\pi \sigma}} \sqrt{\mathrm{f}}(\mathrm{H} / \mathrm{m})
\end{aligned}
$$

\section{Towing Cable Model based on Multi Conductor Transmission Line}

The series impedance matrix of the towing cable is $Z_{0}=R_{0}+j \omega L_{0}$, and its shunt admittance matrix is $Y_{0}=j \omega C_{0}$. Because the outermost shell of the towing cable is the shield shell, The diagonal element $Z_{\mathrm{ii}}$ of the $Z_{0}$ is the self-impedance impedance of the conductor to the shield for the unit length and diagonal element $Z_{\mathrm{ik}}$ is the mutual impedance between the inner and outer conductors ${ }^{[13]}$.

The simplified formulas for calculating the self-impedance and mutual impedance are such as formula (14) and (15).

$$
\begin{aligned}
& \mathrm{Z}_{\text {ii }}=\mathrm{R}_{\text {internal }}+\mathrm{j}\left(\omega \frac{\mu_{0}}{2 \pi} \ln \frac{2\left(\mathrm{~d}_{\mathrm{i}}+\mathrm{p}\right)}{\mathrm{r}_{\mathrm{i}}}+\mathrm{X}_{\text {internal }}\right) \\
& \mathrm{Z}_{\mathrm{ik}}=\mathrm{Z}_{\mathrm{ki}}=\mathrm{j} \omega \frac{\mu_{0}}{2 \pi} \ln \frac{\sqrt{\left(\mathrm{d}_{\mathrm{i}}+\mathrm{d}_{\mathrm{k}}+2 \mathrm{p}\right)^{2}+\mathrm{x}_{\mathrm{ik}}^{2}}}{\mathrm{~d}_{\mathrm{ik}}}
\end{aligned}
$$

Where $\mu_{0}$ is the permeability, $d_{i}$ and $d_{k}$ are respectively the distance of inner and outer conductors to the shield shell, $d_{i k}$ is the distance between the conductors, $p=\sqrt{\rho / j \omega \mu_{0}}, r_{i}$ is the radius of the wire.

Based on the multi conductor transmission line theory, the transmission line equation of $d x$ length element can be written as 


$$
\left\{\begin{array}{l}
\frac{\mathrm{d}}{\mathrm{dz}} V(\mathrm{z})=-Z I(\mathrm{z}) \\
\frac{\mathrm{d}}{\mathrm{dz}} I(\mathrm{z})=-Y U(\mathrm{z})
\end{array}\right.
$$

It is converted into second-order decoupled ordinary differential equations.

$$
\left\{\begin{array}{l}
\frac{\mathrm{d}^{2}}{\mathrm{dz}^{2}} V(\mathrm{z})=Z Y V(\mathrm{z}) \\
\frac{\mathrm{d}^{2}}{\mathrm{dz}^{2}} I(\mathrm{z})=Y Z I(\mathrm{z})
\end{array}\right.
$$

In general, $\mathrm{ZY}$ and $\mathrm{YZ}$ are not diagonal matrices, so the equations could not be solved directly. Mode theory is used to decouple the equation by the voltage conversion matrix $\mathrm{T}_{\mathrm{V}}$ and the current transition matrix $\mathrm{T}_{\mathrm{I}}$. The voltage and current of each model is equal to the wave equation of the independent homogeneous system. And they are independent of each other. Hence the transmission line equation can be written as

$$
\left\{\begin{array}{c}
V(\mathrm{z})=\mathrm{T}_{\mathrm{V}} \mathrm{V}_{\mathrm{m}}(\mathrm{z}) \\
I(\mathrm{z})=\mathrm{T}_{\mathrm{I}} \mathrm{I}_{\mathrm{m}}(\mathrm{z})
\end{array}\right.
$$

Where $\mathrm{V}_{\mathrm{m}}(\mathrm{z}), \mathrm{I}_{\mathrm{m}}(\mathrm{z})$ are column vectors of the mode voltage and the mode current. Therefore, the formula (17) is converted to

$$
\left\{\begin{array}{c}
\frac{\mathrm{d}^{2}}{\mathrm{dz}^{2}} \mathrm{~V}_{\mathrm{m}}(\mathrm{z})=\mathrm{T}_{\mathrm{V}}^{-1} Z Y \mathrm{~T}_{\mathrm{V}} \mathrm{V}_{\mathrm{m}}(\mathrm{z})=\gamma^{2} \mathrm{~V}_{\mathrm{m}}(z) \\
\frac{\mathrm{d}^{2}}{\mathrm{dz}^{2}} \mathrm{I}_{\mathrm{m}}(\mathrm{z})=\mathrm{T}_{\mathrm{I}}^{-1} Y Z \mathrm{~T}_{\mathrm{I}} \mathrm{I}_{\mathrm{m}}(\mathrm{z})=\gamma^{2} \mathrm{I}_{\mathrm{m}}(z)
\end{array}\right.
$$

Because of $\mathrm{T}_{\mathrm{I}}^{\mathrm{t}}=\mathrm{T}_{\mathrm{V}}^{-1}$,

$$
\mathrm{T}_{\mathrm{V}}^{-1} \mathrm{ZYT}_{\mathrm{V}}=\mathrm{T}_{\mathrm{I}}^{-1} \mathrm{YZT}_{\mathrm{I}}=\left[\begin{array}{ccc}
\gamma_{1}^{2} & \cdots & 0 \\
\vdots & \ddots & \vdots \\
0 & \cdots & \gamma_{\mathrm{n}}^{2}
\end{array}\right]
$$

Where $\gamma_{i}^{2}(i=1,2, \ldots n)$ is the characteristic value of $\mathrm{ZY}$ and YZ. The towing cable is considered as a $2 n$ port network, and the voltage and current at the distance 1 from the transmitting terminal are as follows:

$$
\left[\begin{array}{c}
\mathrm{U}(1) \\
\mathrm{I}(1)
\end{array}\right]=\left[\begin{array}{ll}
\mathrm{A}_{11} & \mathrm{~A}_{12} \\
\mathrm{~A}_{21} & \mathrm{~A}_{22}
\end{array}\right]\left[\begin{array}{c}
\mathrm{U}(0) \\
\mathrm{I}(0)
\end{array}\right]
$$

Where U (l) and I (1) are the voltage vector and current vector at the $1, \mathrm{U}(0)$ and I (0) are the voltage vector and current vector at the transmitting terminal. The entire towing cable in accordance with the length of $\mathrm{L}$ is divided into $\mathrm{N}$ parts. If the length of each section can be seen as electrically short for the frequency, that is

$$
\frac{\mathrm{l}}{\mathrm{N}}<<\lambda=\frac{\mathrm{v}}{\mathrm{f}}
$$

So each part can be used to characterize the lumped model. As the frequency increases the transmission lines must be divided more finely. The 4 parameters of the Pi structure and the $\mathrm{T}$ structure of the lumped model are as follows.

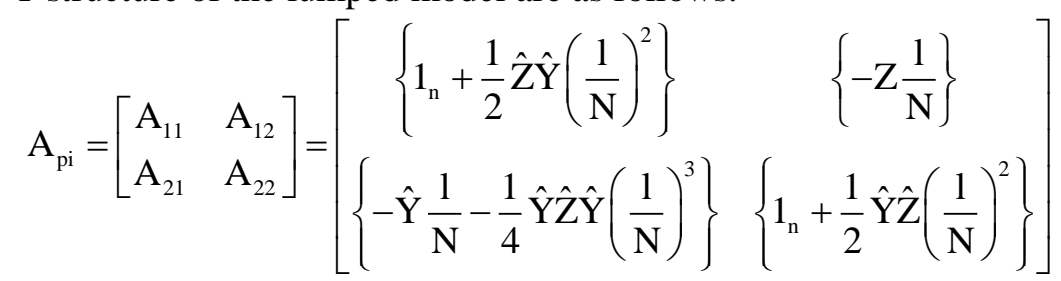




$$
A_{T}=\left[\begin{array}{ll}
A_{11} & A_{12} \\
A_{21} & A_{22}
\end{array}\right]=\left[\begin{array}{cc}
\left\{1_{n}+\frac{1}{2} \hat{Z} \hat{Y}\left(\frac{1}{N}\right)^{2}\right\} & \left\{-\hat{Z} \frac{1}{N}-\frac{1}{4} \hat{Z} \hat{Y} \hat{Z}\left(\frac{1}{N}\right)^{3}\right\} \\
\left\{-Y \frac{1}{N}\right\} & \left\{1_{n}+\frac{1}{2} \hat{Y} \hat{Z}\left(\frac{1}{N}\right)^{2}\right\}
\end{array}\right]
$$

The $\hat{Z}$ is the unit impedance matrix of towing cable, and the $\hat{Y}$ is the unit admittance matrix of towing cable.

\section{Simulations}

This paper uses the Cadence/PSPICE software to build the simulation model of the single Pi structure, double Pi structure and T structure as shown in Figure 2-4.

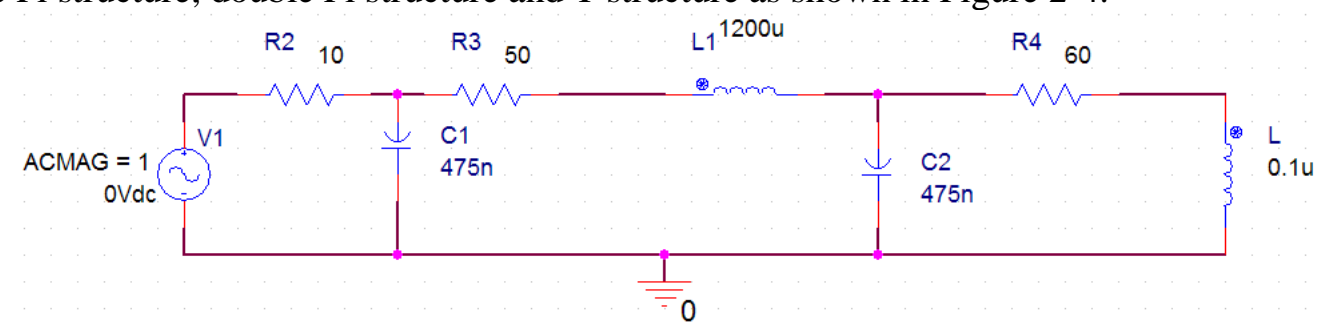

Figure 2. The Model of the Single Pi Structure

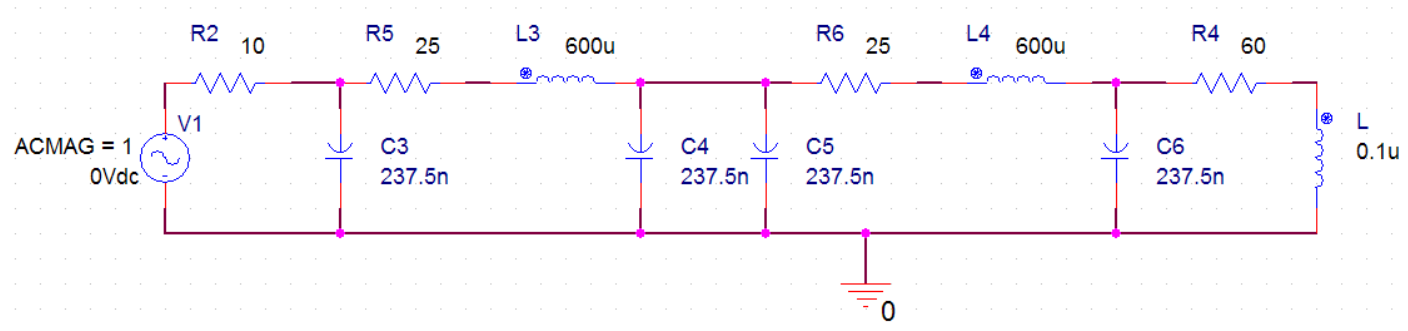

Figure 3. The Model of the Double Pi Structure

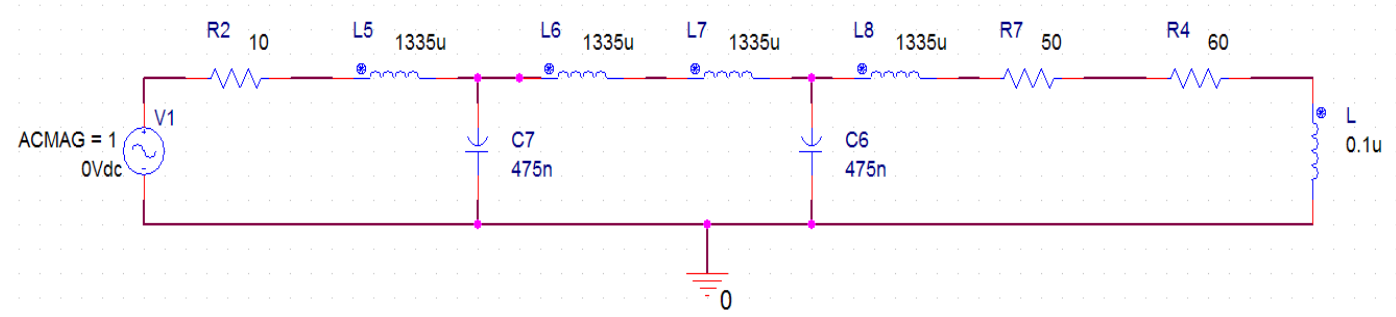

Figure 4. The Model of the T Structure

In the simulation setting, the AC small signal and noise analysis models is selected. Signal source V1 is set to $81 \mathrm{dBm}$, the amplitude is 1 , and the phase is 0 . In order to obtain the $81 \mathrm{dBm}$ transmission power for $\mathrm{V} 1$, its internal resistance as $10 \mathrm{ohms}$. Carrier frequency is from $100 \mathrm{~Hz}$ to $1 \mathrm{MHz}$. Among the structure, units of the resistance R, inductance $\mathrm{L}$ and capacitance $\mathrm{C}$ are respectively as the international unit $\Omega, \mathrm{H}$ and $\mathrm{F}$. The receiver is located in the marine electromagnetic exploration system under water about $10 \mathrm{~km}$; the internal resistance is $60 \mathrm{ohm} / 0.1 \mathrm{uH}$. The simulation results are as follows. 


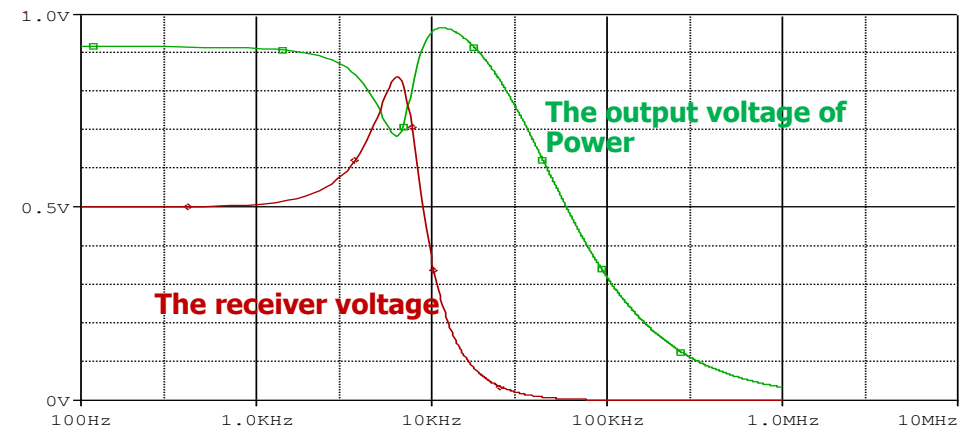

Figure 5. The Simulation Result of the Single Pi Structure

The figure shows the simulation results for the single Pi structure. The power supply voltage drops rapidly but the receiver voltage rises rapidly after the first inflection point which is at $3.5 \mathrm{kHz}$. And when the frequency is $6.5 \mathrm{kHz}$, the power supply voltage is reduced to a minimum but the receiver voltage rises to maximum. However, the receiver voltage is greater than the supply voltage from $5.0 \mathrm{kHz}$ to $7.3 \mathrm{kHz}$, which could not communicate. When the frequency is $13 \mathrm{kHz}$, there is second inflection point. At this time the receiver can receive the minimum voltage but the power supply voltage rises to maximum. Then the frequency exceeds $16 \mathrm{kHz}$, both the power supply voltage and the receiver voltage are rapidly fading. The power supply has been unable to output after 30 $\mathrm{kHz}$.

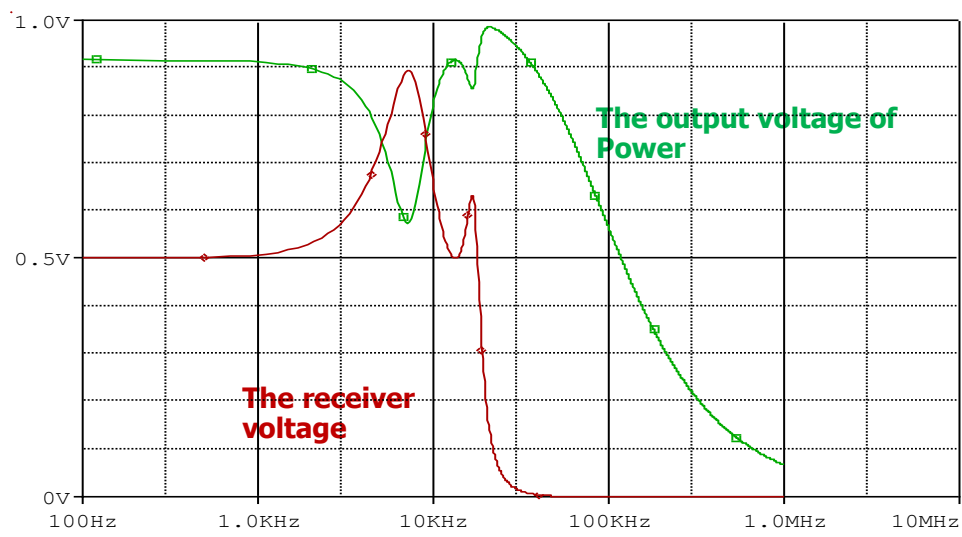

Figure 6. The Simulation Result of the Double Pi Structure

The figure shows the simulation results for the double Pi structure. Like the single Pi structure, the power supply voltage drops rapidly after the first inflection point which is at $4 \mathrm{kHz}$. And when the frequency is $7 \mathrm{kHz}$, the power supply voltage is reduced to a minimum but the maximum for the receiver. However, the receiver voltage is greater than the supply voltage from $5.0 \mathrm{kHz}$ to $9.0 \mathrm{kHz}$, which could not communicate. When the frequency is $13 \mathrm{kHz}$, there is second inflection point. At this time the receiver could get the minimum voltage but the maximum for the power supply. However, different from the single Pi structure is that when the frequency is $16 \mathrm{kHz}$, there is third inflection point. At this point, the receiver voltage reaches the peak value again, and the power supply voltage reaches the minimum value .Then the frequency exceeds $16 \mathrm{kHz}$, the receiver voltage decays rapidly. At last the power supply has been unable to output after $30 \mathrm{kHz}$. 


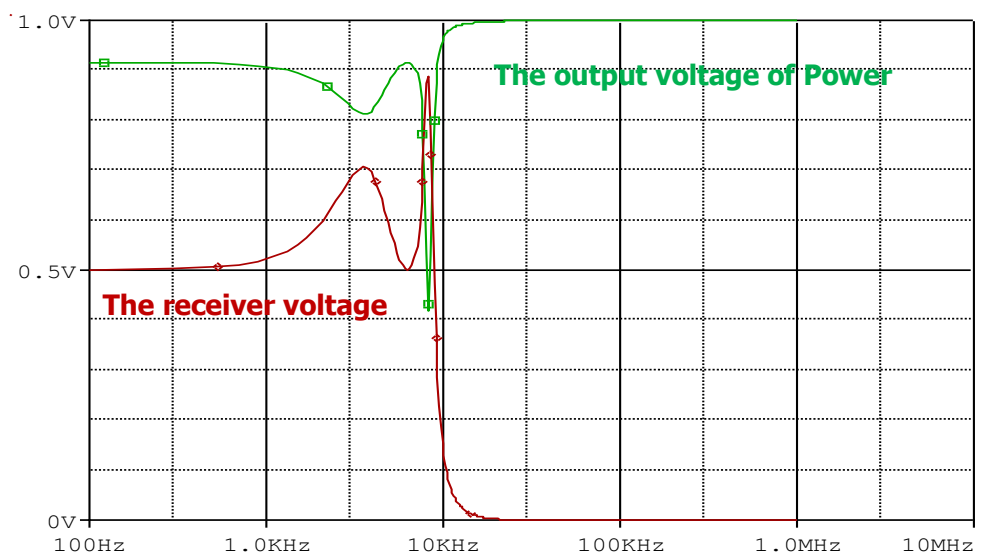

Figure 7. The Simulation Result of the T Structure

The figure shows the simulation results for the double $\mathrm{T}$ structure. It is different from the single Pi structure and the double Pi structure. The power supply voltage drops rapidly but the receiver voltage rises after the first inflection point which is at $4 \mathrm{kHz}$. And when the frequency is $6.5 \mathrm{kHz}$, the power supply voltage is reduced to a minimum but the maximum for the receiver. There is third inflection point at $8.3 \mathrm{kHz}$, where the power supply voltage is reduced to a minimum but the maximum for the receiver. After this frequency the receiver voltage decays rapidly. At last the power supply has been unable to output after $15 \mathrm{kHz}$. However, the receiver voltage is greater than the supply voltage from $7.7 \mathrm{kHz}$ to $8.6 \mathrm{kHz}$, which could not communicate.

The actual measurement of the $\mathrm{T}$ structure could not accurately reflect the actual working mode of the channel, and the double PI structure is a large amount of calculation. Therefore, the single Pi structure is confirmed.

The transmitted signal is $81 \mathrm{~dB}(25 \mathrm{~W})$. Meanwhile,the minimum power of the receiver must be greater than or equal to $-100 \mathrm{~dB}$ ( The signal will be lost in the background noise below this value).The receiving signal power could be calculated by the following formula.

$$
\mathrm{P}_{\mathrm{N}^{* 1}}=10 \bullet \lg \left(\mathrm{I}_{\mathrm{N}^{* 1}} \bullet \mathrm{V}_{\mathrm{N}^{* 1}}\right) \bullet 1000
$$

Wherein $\mathrm{P}_{\left(\mathrm{N}^{*} 1\right)}$ is the receiver signal power. So the receiver signal power of the 3 structures is obtained.
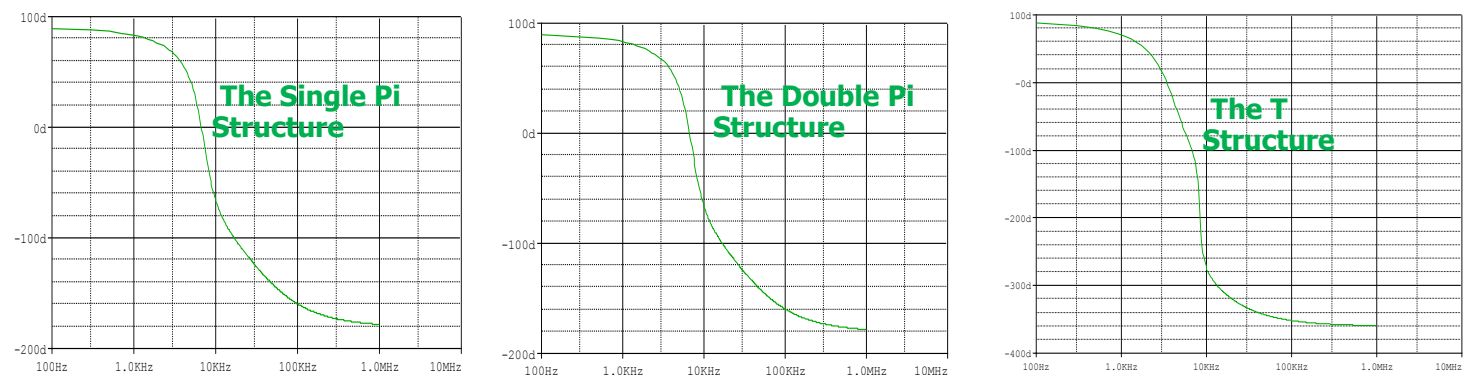

Figure 8: The Curves of the 3 Structures

From the above curves, the receiving signal curve of the single Pi structure is basically consistent with the double Pi structure, but it is larger different with the curve of the T structure. T-type structure has rapidly decay power at $3 \mathrm{kHz}$. And the receiver could not get the signal after $6.5 \mathrm{kHz}$. Nevertheless, the power can basically keep consistent around $3 \mathrm{kHz}$ for the single Pi structure and the double Pi structure. The receiver basically could not receive the signal until $13 \mathrm{kHz}$. 


\section{Experimental}

In this experiment, the inner conductor of towing cable is used AWG1 line (19*0.945), which consists of 19 shares copper wire with $0.945 \mathrm{~mm}$ diameter. And the outer conductor uses AWG20 line with 1 shells of $0.813 \mathrm{~mm}$ diameter. The structure of the towing cable is shown in Figure 9 and Table 1.

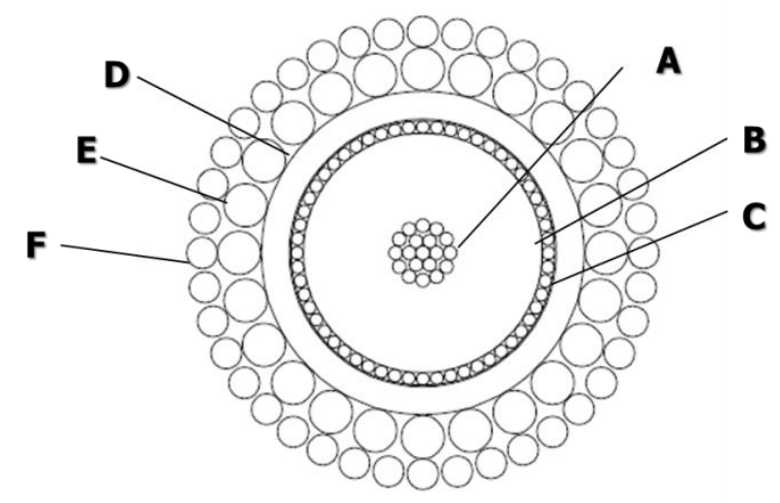

Figure 9. The Structure of the Towing Cable

Table 1. The Parameters of the Towing Cable

\begin{tabular}{ccc}
\hline Number & Description & $\mathrm{D}(\mathrm{mm})$ \\
$\mathrm{A}$ & AWG1 & 3 \\
$\mathrm{~B}$ & INSULATION & 10.72 \\
$\mathrm{C}$ & AWG20 & 11.86 \\
$\mathrm{D}$ & BELT & 14.48 \\
$\mathrm{E}$ & ARMOR/Shell 1 & 18.39 \\
$\mathrm{~F}$ & ARMOR/ Shell 2 & 21.20 \\
\hline
\end{tabular}

The distribution resistance, inductance and capacitance of the $10 \mathrm{~km}$ towing cable are tested using the LCR instrument as shown in the following table. Among them, 0.2, 0.5, 1 and $10 \mathrm{~km}$ are the measured values, and the other is the theoretical calculation.

Table 2. The Measured Values of RLC

\begin{tabular}{cccc}
\hline Length/km & $\mathrm{R} / \Omega$ & $\mathrm{L} / \mathrm{uH}$ & $\mathrm{C} / \mathrm{nF}$ \\
0.2 & 1.00 & 24.00 & 19.00 \\
0.5 & 2.52 & 60.20 & 48.50 \\
0.8 & 4.90 & 121.80 & 96.00 \\
1 & 4.99 & 120.35 & 96.80 \\
2 & 12.25 & 304.50 & 240.00 \\
5 & 24.50 & 609.00 & 480.00 \\
10 & 50.00 & 1200.00 & 950.00 \\
\hline
\end{tabular}

From the above table, the result could be seen that the measured values are in agreement with the theoretical calculation, and there is no big discrepancy between them.

Used digital oscillator and digital frequency selective meter measures the voltage of the receiver. The power supply voltage is $1 \mathrm{~V}(81 \mathrm{db})$, transmit and receive impedance is 50 ohms. Curve fitting of measurement and simulation structure using MATLAB, its result are shown in Figure 10. 


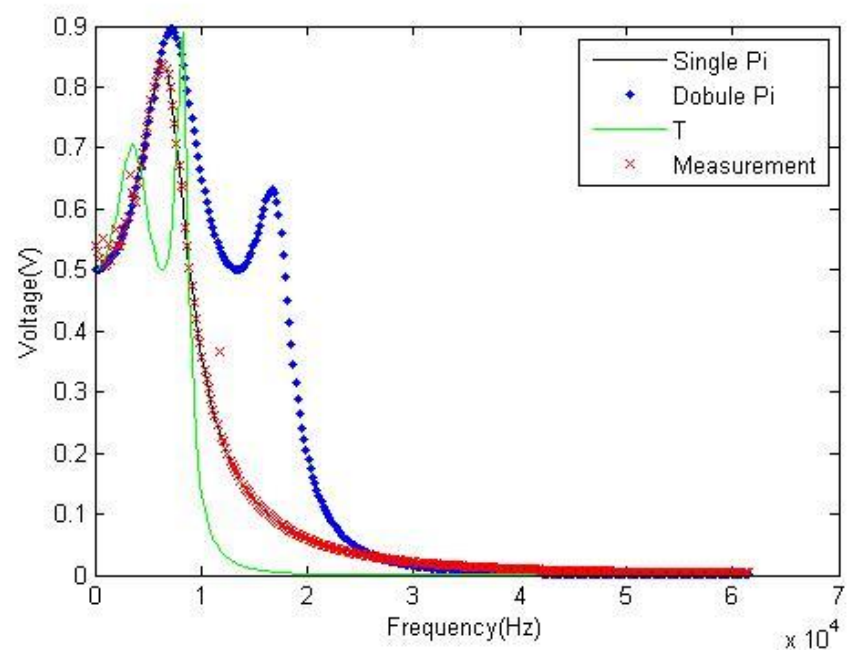

Figure 10: Comparison of Simulation and Measurement Results for Receiver Voltage

It can be seen from the figure that the single Pi structure measurement of the receiver voltage is in agreement with the simulated voltage value. It is only different in low frequency, but this does not affect the analysis of the actual communication.

\section{Conclusions}

A carrier communication channel model of marine electromagnetic exploration system based on multi conductor transmission line is established in this paper. The basic impedance value of towing cable is obtained by impedance measurement. The single $\mathrm{Pi}$ structure, double Pi structure and T structure cable simulation model have been set up through the Spice. The accuracy of single Pi structure model was verified by measurement and simulation. The parameters of this model are easy to be calculated and measured. Accordingly the model could be used to analyze the design of the communication frequency band and the coupling circuit in order to facilitate the application of different modulation and coding technology in marine electromagnetic exploration. It provides a guiding role for the whole communication system.

\section{Acknowledgements}

Authors wishing to acknowledge assistance or encouragement from colleagues, financial support by R\&D of Key Instruments and Technologies for Deep Resources Prospecting (the National R\&D Projects for Key Scientific Instruments), Grant No. XDB06030200.

\section{References}

[1] F. Chen, W. Zheng and C. Sheng, "Low-voltage power line carrier communication technology and its application", Power System Protection and Control, vol. 188, no. 22, (2009).

[2] S. Siami, C. Joubert and C. Glaize, "High frequency model for power electronics capacitors", IEEE Transactions on Power Electronics, vol. 157, no. 16, (2001).

[3] C. Wei, L. Jian and L Kaipei, "A channel modeling technology for the medium-voltage power-line carrier in smart power distribution grid", Proceedings of the CSEE.150, vol. 32, (2012).

[4] B. Caldon, "Distribution line carrier: analysis procedure and applications to DG", IEEE Transactions on Power Delivery, vol. 575, no. 22, (2007).

[5] S. Galli, T. A. Banwell, "novel approach to the modeling of the indoor power line channel, part II:transfer function and its properties", IEEE Transactions on Power Delivery.3, 20, (2005).

[6] F. Su, H. Liu and Q.Wang, "Application of power / signal transmission technology in underwater production system”, Petrochemical Automation, vol. 5, no. 29, (2008). 
[7] L. Zhang, "Design of subsea production control systems", Shipbuilding of china, vol. 1, no. 51, (2010).

[8] H. Shorten V, Stein V. Power line communication device for subsea well. U.S. Patent, vol. 8, no.052, 940, (2010).

[9] V. Horten and V. Steigen, "Modem in particular for subsea power line communication. U.S. Patent 8, vol. 279 , no. 614 , (2012).

[10] E. Brekke, V. Horten and V. Steigen, "Method and modem for subsea power line communication [P]. U.S. Patent 8, vol. 199, no. 798, (2012).

[11] S. Wang, Y. Liu, H. Cao, L. Guo,Y. Wang, L. Zhu and J. Tian, "Simulation study on power line carrier communication design for subsea production control syste", Ocean engineering equipment and technology, vol. 2, no. 64, (2015).

[12] J. Anatory, N. Theethayi and R. Thottappillil, "Power-line communication channel model for interconnected networks, part II :multi conductor system", IEEE Transactions on Power Delivery, vol. 24, no. 124, (2009).

[13] H. W. Dommel, "EMTP theory book", USA: Bonneville Power Administration, Columbia, (1986).

\section{Authors}

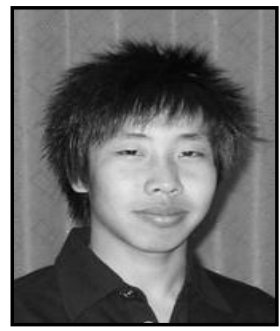

Ren Xiguo, he is from Hebei, China, Beijing University of Technology, PhD, scientific interest: Power electronic, Communications technology, switching supply. E-mail: xiaoxifree@126.com

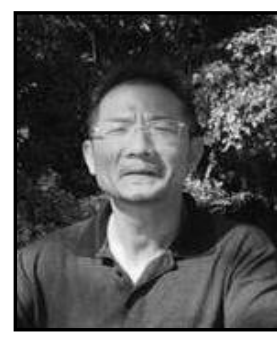

Zhang Yiming, he is from, Hubei, china, Beijing University of Technology, Professor, $\mathrm{PhD}$, scientific interest: intelligent power management, motor speed control, servo drives, and motor energy conservation. E-mail: ymzhang@ bjut.edu.cn

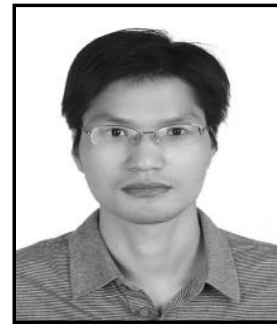

Tao Haijun, he is from, Henan, China, Beijing University of Technology, and $\mathrm{PhD}$, taught at the University of Henan Polytechnic University, Lecturer, and scientific interest: Power electronic, Communications technology, switching supply. E-mail: taohj99@hpu.edu.cn

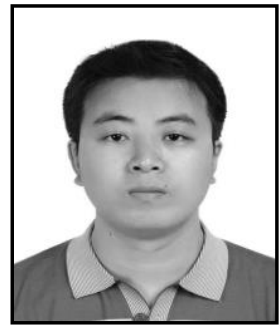

Zeng Zhihui, he is from Jiangxi, China, University of Henan Polytechnic University, associate professor, $\mathrm{PhD}$, scientific interest: signal processing, Power electronic, Communications technology, Energy storage technology. E-mail: zzhh@hpu.edu.cn

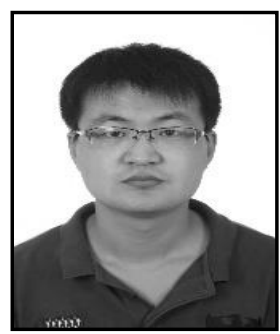

Ding Jianzhi, he is from Liaoning, China, Beijing University of Technology, PhD, scientific interest: High frequency power conversion, geophysical prospecting converter, switching supply. Email: djzh5@163.com 
International Journal of Future Generation Communication and Networking Vol. 9, No.10, (2016) 